\title{
RANCANG BANGUN SISTEM PADI AQUAPONIC BERBASIS IoT(Internet of Things)
}

\author{
Desvianty Ayu Wahyudi, Suryo Adi Wibowo, Renaldi Primaswara P \\ Program Studi Teknik Informatika S1, Fakultas Teknologi Industri \\ Institut Teknologi Nasional Malang, Jalan Raya Karanglo km 2 Malang, Indonesia \\ 1718055@scholar.itn.ac.id
}

\begin{abstract}
ABSTRAK
Padi Aquaponic adalah sistem pertanian dengan metode menanam padi dan memelihara ikan dengan memanfaatkan kotoran ikan sebagai nutrisi pada padi. Dalam budidaya padi Aquaponic sering dijumpai permasalahan, sampai saat ini sistem padi Aquaponic masih dilakukan secara manual seperti memantau keadaan dari aliran pompa air, kelembaban tanah, kekeruhan air kolam dan pengendalian hama padi. Dari permasalahan yang diuraikan diatas untuk itu dikembangkanlah sistem padi Aquaponic dengan konsep IoT (Internet Of Things) dapat dilakukan monitoring jarak jauh pada hardware atau alat menggunakan website dengan bantuan akses internet. Disamping itu ditambahkanya motor servo sebagai aktuator kendali buka dan tutup agar kabut dari pestisida yang dihasilkan oleh mist maker. Sistem kendali tersebut juga diterapkan sama dengan sistem pemberian pakan pada ikan, dengan pengaturan waktu pada modul RTC (Real Time Clock). Kemudian dibuat pula filtering air kolam otomatis jika terdeteksi air kolam keruh. Hasil pengujian menunjukkan bahwa rata -rata persentase error pada sensor kelembaban 3.49\% dan sensor debit 3.16\%. Dari hasil pengujian kamera ESP32-Cam dapat diketahaui bahwa nilai IP yang diberikan sama / tetap. Website berjalan dengan baik di berbagai browser web (Opera, Google Chrome dan Microsoft Edge) karena aplikasinya merupakan website responsive yang dibuat menggunakan pemrograman PHP.
\end{abstract}

Kata kunci : Padi Aquaponic, Arduino, IoT, Monitoring, Website

\section{PENDAHULUAN}

Padi merupakan tanaman pangan tepenting karena tergolong sebagai salah satu kebutuhan pangan dunia khususnya bagi masyarakat Indonesia. Semakin meningkatnya kebutuhan beras, peran budidaya padi sangat penting. Kurangnya luas lahan dan lahan yang kurang memadai di perkotaan Indonesia menjadi masalah utama untuk memulai budidaya padi, karena tingginya tingkat pertumbuhan penduduk akan kebutuhan lahan untuk keperluan non pertanian seperti perumahan, pusat perbelanjaan, dll. Terlebih dari permasalahan yang ada di wilayah Kalimantan khususnya Kota Tarakan, karena belum adanya sawah untuk menghasilkan kebutuhan pangan seperti beras. Padi Aquaponic merupakan solusi budidaya yang cocok untuk wilayah Kota Tarakan.

Sistem Aquaponic merupakan gabungan antara sistem akuakultur dan budidaya tanaman hidroponik. Dalam sistem ini ikan dan tumbuhan akan tumbuh dalam satu sistem yang terintegrasi dan menciptakan hubungan simbiosis antar keduanya. [2]

Padi Aquaponic adalah sistem pertanian yang menggabungkan budidaya dan hidroponik dalam lingkungan simbiosis atau hidup dengan budidaya padi dan ikan. Aquaponic merupakan salah satu cara menanam padi dan memelihara ikan dengan memanfaatkan kotoran ikan sebagai nutrisi. Sedangkan hidroponik adalah metode bercocok tanam yang menggunakan media air untuk mengolah dan memberi nutrisi secara terpisah. [3]

Dalam budidaya padi Aquaponic ada beberapa permasalahan yang sering dijumpai. Sampai saat ini sistem budidaya padi Aquaponic masih dilakukan secara manual, seperti pemantauan kondisi aliran pompa air, kelembaban tanah, kekeruhan air tambak dan pengendalian hama padi. Sistem ini belum bisa dikatakan efektif karena petani Aquaponic tidak selalu bisa memantau setiap saat di tempat. Untuk itu, diperlukan sistem baru yang dapat membantu menyelesaikan permasalahan tersebut.

Dari permasalahan diatas untuk itu dikembangkanlah sistem padi Aquaponic dengan konsep IoT (Internet Of Things) yang sangat luas penggunaanya. Dengan memanfaatkan konsep IoT, dapat dilakukan monitoring jarak jauh pada hardware atau alat dengan menggunakan Website dan bantuan akses internet. Disamping itu ditambahkanya motor servo sebagai aktuator kendali buka dan tutup agar kabut dari pestisida yang dihasilkan oleh mist maker keluar tertuju pada padi. Sistem kendali tersebut juga diterapkan sama dengan sistem pemberian pakan pada ikan, dengan pengaturan waktu pada modul RTC (Real Time Clock).

\section{TINJAUAN PUSTAKA \\ 2.1 Penelitian Terkait}

Dianna Ratnawati dan Bayu Rahmat Setiadi melakukan penelitian yang berjudul "Techno-Pest Control Berbasis IoT untuk Proteksi Tanaman Padi”. Dengan tujuan penelitian untuk mengusir atau memberantas hama wereng dan belalang dengan mengetahui dampak penggunaan techno-pest control dalam pengendalian wereng da $\mathrm{n}$ belalang. Pada penelitian ini dilakukan eksperimen dengan alat uji pada jarak $3 \mathrm{~m}$ dan $6 \mathrm{~m}$. Teknologi yang dihasilkan berbasis IoT (Internet Of Things) yang diatur dengan frekuensi $40 \mathrm{kHz}$ dan dikendalikan melalui smartphone. Teknologi ini 
dilengkapi dengan kamera IP sebagai monitoring kondisi persawahan dimana hasil percobaan pada jarak

mampu membunuh wereng dan belalang dalam waktu 8 jam. Sedangkan pada jarak $6 \mathrm{~m}$ dapat membunuh kedua hama tersebut dalam waktu 13 jam. Pada tahap awal hama menunjukkan reaksi diam karena metabolisme terganggu oleh efek suara yang dikeluarkan alat tersebut, kemudian lama kelamaan hama akan mati. Sehingga dapat disimpulkan bahwa techno-pest control cocok digunakan dengan kombinasi alat-alat dengan konsep IoT sebagai teknologi pelindung tanaman padi dari wereng dan belalang yang ramah lingkungan di persawahan. [4]

Eduardus Tuluk, Irawadi Buyung, dan Ajie Wibowo Soejono melakukan penelitian yang berjudul "Implementasi Alat Pengusir Hama Burung di Area Persawahan dengan Mengunakan Gelombang Ultrasonic Berbasis Mikrokontroler Atmega 168". Dalam penelitian ini bertujuan untuk mengusir hama burung dengan frekuensi $20-25 \mathrm{KHz}$ berdasarkan habitat dari hama tersebut, namun dalam penelitian ini tingkat frekuensi yang dapat digunakan untuk mengusir hama belum ditentukan. Rangkaian elektronika yang digunakan meliputi rangkaian mikrokontroler ATmega 168, rangkaian laser (pemancar sinar), rangkaian LDR (penerima sinar), buzzer, dan LCD. [5]

Anwar Mujadin melakukan penelitian yang berjudul "Prototype Chamber Pengaturan Suhu, Kelembaban dan Growing LED Tanaman Aeroponic". Dalam penelitian ini bertujuan untuk mengetahui komposisi spectrum cahaya yang paling tepat untuk laju fotosintesis pada tanaman aeroponic dan factor-faktor yang mempengaruhi pertumbuhan tanaman. Hasil penelitian menujukkan bahwa prototipe berupa ruangan kecil, penyemprotan unsur hara dari kabut ke akar tanaman, sekaligus mengontrol lampu LED, tanaman akan menyerap unsur hara dan berkembang secara optimal berdasarkan data pengamatan. Data berlangsung selama seminggu, setiap kecambah tumbuh $2 \mathrm{~cm}$ perhari, dan berat basah tauge 26 gram per pot. [6]

Rocky Triady, Dedi Triyanto, dan Ilhamsyah telah melakukan penelitian yang berjudul "Prototipe Sistem Keran Air Otomatis Berbasis Sensor Flowmeter pada Gedung Bertingkat". Penelitian ini bertujuan untuk memberikan solusi atas masalah distribusi air pada gedung bertingkat yang memiliki kuota air terbatas dan tidak dapat memenuhi kebutuhan air sehari-hari. Penggunaan mikrokontroler Atmega328 pada Arduino Uno dirancang dengan menambahkan beberapa komponen pendukung (seperti flowmeter, selenoid valve dan pompa air) yang dibuat menjadi sistem keran otomatis. Dari hasil perancangan ini dapat diketahui bahwa pada saat diberikan instruksi pembukaan otomatis maka kran akan ditutup dan dilajutkan dengan membuka kran berikutnya. Jika kran dijalankan secara manual, kran akan hidup dan mati sesuai dengan instruksi pada tombol di antarmuka pengguna. [7]

Achmat Fahrul Taufiqurrohman, Suryo Adi Wibowo, FX Ariwibisono melakukan penelitian yang

berjudul "Penerapan IoT (Internet Of Things) Untuk Memonitoring Penggunaan Kadar Infus dan Kondisi

Pasien Yang Sedang Membutuhkan Perawatan”. Dengan perkembangan teknologi ini, rumah sakit bisa memantau kondisi pasien. Kondisi tersebut hanya dilihat melalui ruang perawat di layer monitor berbasis website yang mecantumkan semua data termasuk nama pasien, ruangan, dan kondisi pasien. Dalam pengembangan ini memiliki fitur yang dapat membantu pengguna biasa dan tabel website yang dapat berubah warna sesuai kondisi pasien yaitu warna merah, kuning, dan hijau. Warna merah berarti kondisi pasien harus segera dirawat untuk mengganti infus atau mengecek kondisi pasien, warna kuning berarti infus pasien akan segera selesai karena volume infus kurang da ri 100 gram, dan warna hijau berarti kondisi pasien baik-baik saja. Fitur lainnya adalah halaman riwayat data pasien yang digunakan untuk melihat data pasien dan file rumah sakit yang telah dirawat, terakhir ada halaman untuk menambahkan data pasien untuk pasien yang baru datang. [8]

\subsection{IoT (Internet Of Things)}

Internet of Thing (IoT) adalah konsep suatu objek yang memiliki kemampuan untuk mengirimkan data melalui jaringan tanpa memerlukan interaksi manusiamanusia atau manusia-komputer. Menurut analisis McKinsey Global Institute, Internet of Things adalah teknologi yang dapat menghubungkan mesin, peralatan, objek fisik lainnya dengan sensor dan akuator jaringan untuk memperoleh data dan mengelola kinerjanya sendiri, sehingga mesin dapat berkolaborasi dan bahkan bertindak berdasarkan New informasi yang diperoleh secara mandiri. Oleh karena itu, dapar disimpulkan bahwa Internet of Things dapat menjalin koneksi antar mesin, sehingga mesin tersebut dapat berinteraksi dan bekerja secara mandiri berdasarkan data yang diperoleh dan diolah secara mandiri. [9]

\subsection{Smart Farming}

Smart Farming yaitu Teknologi Wireless Sensor Network (WSN) banyak digunakan dibidang pertanian berbasis Internet Of Things. Pertanian cerdas yang semula disebut pertanian presisi diharapkan menjadi konsep pertanian dimasa mendatang karena keterbatasan lahan. pPertanian cerdas menggunakan tekonologi seperti big data, machine learning, robotika, dan Internet Of Things untuk meningkatkan kualitas dan kuantitas produksi industri pertanian. [10]

\subsection{Website}

Website adalah kumpulan informasi atau halaman yang bisa diakses melalui internet. Selama bisa terhubung secara online di internet, semua orang disetiap tempat dapat menggunkannya [11]. Website pada sistem digunakan sebagai pusat monitoring padi Aquaponic berbasis IoT (Internet Of Things).

\section{RANCANGAN SISTEM}

Penelitian ini akan membahas mengenai perancangan Sistem Padi Aquaponic Berbasis IoT (Internet Of Things).

\subsection{Analisis Kebutuhan Fungsional}

Dalam merancang sistem padi Aquaponic ada beberapa kebutuhan fungsional antara lain : 
Tabel 1. Kebutuhan Fungsional

\begin{tabular}{|l|l|c|}
\hline No. & \multicolumn{1}{|c|}{ Hardware } & \multicolumn{1}{c|}{ Software } \\
\hline 1 & Arduino Uno R3 & $\begin{array}{l}\text { Arduino } \\
\text { DE 1.8.13 }\end{array}$ \\
\hline 2 & Modul ESP8266 & Visual Code \\
\hline 3 & $\begin{array}{l}\text { Sensor } \\
\text { Kelembaban (Soil } \\
\text { Moisture) }\end{array}$ & XAMPP \\
\hline 4 & $\begin{array}{l}\text { Sensor Debit Air } \\
\text { (Flowmeter) }\end{array}$ & $\begin{array}{c}\text { Web } \\
\text { browser }\end{array}$ \\
\hline 5 & $\begin{array}{l}\text { Sensor Kekeruhan } \\
\text { (Turbidity) }\end{array}$ & - \\
\hline 6 & ESP32-cam & - \\
\hline 7 & $\begin{array}{l}\text { Ultrasonic Speaker } \\
\text { Sound }\end{array}$ & - \\
\hline 8 & Pompa Air & - \\
\hline 9 & Dc Fan & - \\
\hline 10 & Mist Maker & - \\
\hline 11 & Motor Servo & $\begin{array}{l}\text { RTC Real Time } \\
\text { Clock) }\end{array}$ \\
\hline 12 & \multicolumn{2}{|l}{} \\
\hline
\end{tabular}

\subsection{Diagram Blok Sistem Monitoring Padi} Aquaponic

Sistem monitoring padi Aquaponic dengan mikrokontroler Arduino Uno sebagai pengelola data dari sensor. Data kelembaban tanah (\%), data debit air, dan data keruh (NTU) akan dikirim dan diolah oleh Arduino Uno. Kemudian, data di simpan ke database melalui modul ESP8266 dan dapat dilihat oleh pengguna atau user pada tampilan website. Blok diagram dari sistem monitoring dapat dilihat pada Gambar 1.

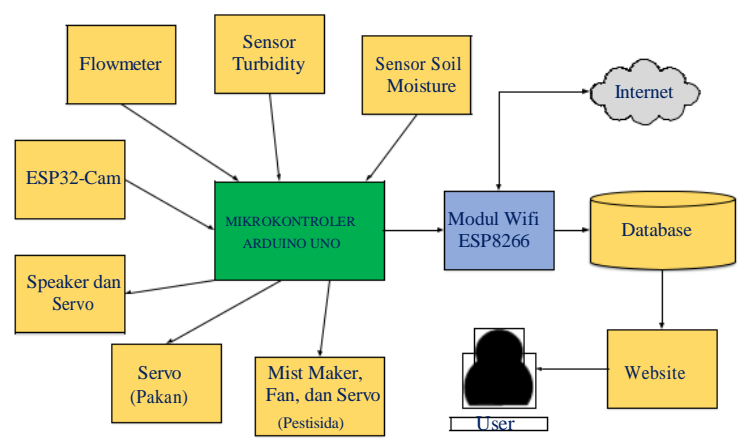

Gambar 1 Diagram Blok Sistem Monitoring Pada Padi Aquaponic

\subsection{Struktur Menu Website}

Website monitoring pada sistem padi Aquaponic terdiri dari empat halaman yaitu halaman home, data monitoring, grafik, dan keadaan abnormal. Berikut stuktur menu pada website dapat dilihat pada Gambar 2.

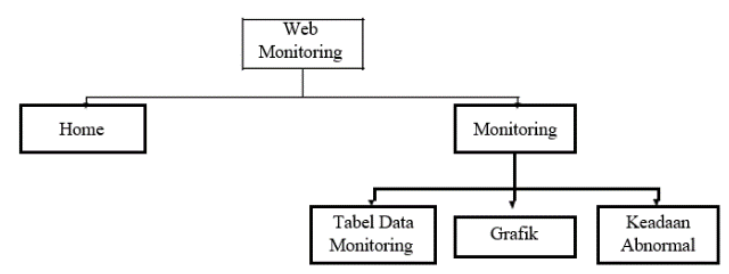

Gambar 2 Struktur Menu Website

3.4. Flowchart Sistem Monitoring Padi Aquaponic Flowchart Sistem Monitoring Padi Aquaponic menjelaskan alur dari sistem monitoring Padi Aquaponic. Flowchart sistem monitoring bisa dilihat pada Gambar 3
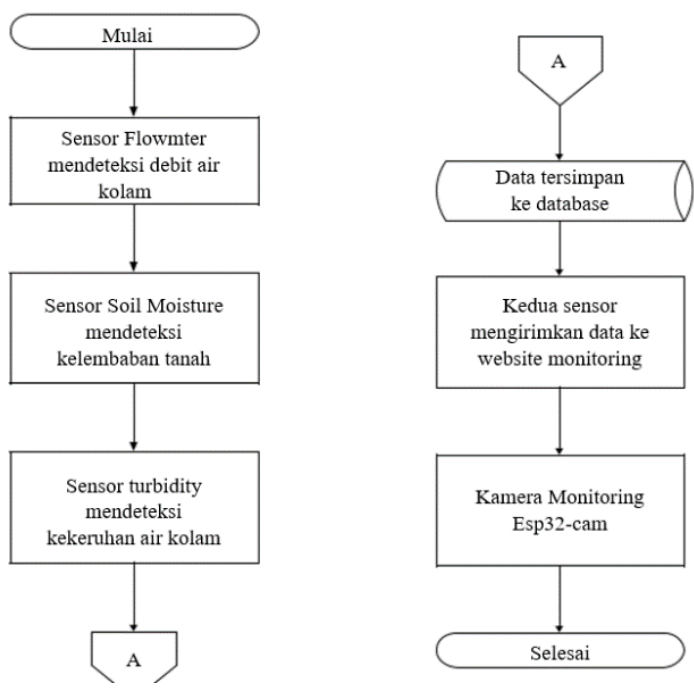

Gambar 3 Flowchart Sistem Monitoring

\section{IMPLEMENTASI DAN PENGUJIAN}

Pada bab ini akan ditunjukkan hasil pengujian dan pembahasan proses yang sudah dilakukan.

\subsection{Pengujian ESP8266}

Pengujian pada modul ESP8266 atau modul wifi ini menggunakan pengujian dengan mengirim data -data dari sensor ke web server. Hasilnya bisa dilihat pada Tabel 2 .

Tabel 2. Pengujian ESP8266

\begin{tabular}{|c|c|c|c|}
\hline \multirow[b]{2}{*}{ No } & \multicolumn{2}{|c|}{ Waktu } & \multirow[b]{2}{*}{$\begin{array}{r}\text { Delay } \\
\text { (Detik) }\end{array}$} \\
\hline & $\begin{array}{c}\text { Waktu } \\
\text { Pengiriman }\end{array}$ & $\begin{array}{c}\text { Waktu } \\
\text { Tampil di } \\
\text { Web }\end{array}$ & \\
\hline 1 & $21: 30: 00$ & $21: 30: 05$ & 5 \\
\hline 2 & $21: 30: 16$ & $21: 30: 21$ & 5 \\
\hline 3 & $21: 30: 33$ & $21: 30: 37$ & 5 \\
\hline 4 & $21: 30: 50$ & $21: 30: 55$ & 5 \\
\hline 5 & $21: 31: 06$ & $21: 31: 11$ & 5 \\
\hline
\end{tabular}

Hasi pengujian dari Tabel 2 dapat diamati bahwa jeda atau dela y pada pengiriman data telah sesuai yaitu 5 detik. Pada serial monitor waktu pengiriman pada pukul 21:30:00 kemudian waktu tampil di web pada pukul 21:30:05 dan seterusnya. 


\subsection{Pengujian ESP32-Cam}

Pengujian kamera Esp32-Cam dilakukan dengan tujuan mengetahui apakah kamera tersebut dapat berfungsi dengan baik, dan hasilnya dapat dilihat pada Gambar 4.

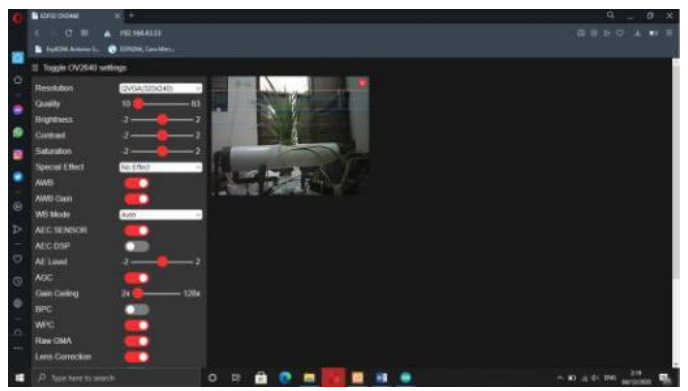

Gambar 4. Pengujian ESP32-Cam

Dari hasil pengujian pada Gambar 4 dengan menerima alamat IP yang telah diberikan pada kamera/ESP32-Cam dalam serial monitor arduino sama saja/tetap. Terdapat beberapa fitur untuk ESP32-Cam dengan mengatur kualitas, kontras, dan lain-lainnya .

\subsection{Pengujian Sensor Soil Moisture}

Dilakukan pengujian kelembaban tanah dengan sensor Soil Moisture pada padi Aquaponic dengan alat banding Three-Way Meter dapat dilihat pada Tabel 3.

Tabel 3. Pengujian Sensor Soil Moisture

\begin{tabular}{|c|c|c|c|c|}
\hline No & $\begin{array}{c}\text { Three-Way } \\
\text { Meter (Moist) }\end{array}$ & Soil moisture & Selisih & Error \\
\hline 1 & 4.00 & 4.00 & 0 & $0 \%$ \\
\hline 2 & 4.00 & 6.00 & 2 & $5.00 \%$ \\
\hline 3 & 5.00 & 2.00 & 3 & $6.00 \%$ \\
\hline 4 & 3.00 & 4.00 & 1 & $3.33 \%$ \\
\hline 5 & 3.00 & 4.00 & 1 & $3.33 \%$ \\
\hline 6 & 5.00 & 7.00 & 2 & $4.00 \%$ \\
\hline 7 & 6.00 & 7.00 & 1 & $1.67 \%$ \\
\hline 8 & 6.00 & 8.00 & 2 & $3.33 \%$ \\
\hline 9 & 7.00 & 10.00 & 3 & $4.29 \%$ \\
\hline 10 & 6.00 & 11.00 & 5 & $8.33 \%$ \\
\hline 11 & 7.00 & 9.00 & 2 & $2.86 \%$ \\
\hline 12 & 7.00 & 10.00 & 3 & $4.29 \%$ \\
\hline 13 & 8.00 & 11.00 & 3 & $3.75 \%$ \\
\hline 14 & 9.00 & 11.00 & 2 & $2.22 \%$ \\
\hline 15 & 10.00 & 10.00 & 0 & $0 \%$ \\
\hline \multicolumn{5}{|c|}{ Rata-rata } \\
\hline
\end{tabular}

Hasil pengujian sensor kelembaban yang dibandingkan dengan Three Way Meter (moist). Dari perbandingan yang diperoleh rata - rata tingkat error sebesar $3.49 \%$ dan perbandingan didapatkan cukup akurat.

\subsection{Pengujian Sensor Flowmeter}

Pengujian Sensor Flowmeter dengan gelas ukur dan pembacaan dari sensor yang bisa dilihat pada Tabel 4.

Table 4. Pengujian Sensor Flowmeter

\begin{tabular}{|c|c|c|c|c|}
\hline No & Gelas Ukur $(\boldsymbol{m l})$ & Flowmeter $(\boldsymbol{m l})$ & Selisih & Error \\
\hline 1 & 100 & 106 & 6 & $6.00 \%$ \\
\hline 2 & 200 & 215 & 15 & $7.50 \%$ \\
\hline 3 & 300 & 318 & 18 & $6.00 \%$ \\
\hline 4 & 400 & 409 & 9 & $2.20 \%$ \\
\hline 5 & 500 & 526 & 26 & $2.94 \%$ \\
\hline 6 & 600 & 630 & 30 & $5.00 \%$ \\
\hline 7 & 700 & 726 & 26 & $3.71 \%$ \\
\hline 8 & 800 & 822 & 22 & $2.75 \%$ \\
\hline 9 & 900 & 921 & 21 & $2.33 \%$ \\
\hline 10 & 1000 & 1017 & 17 & $1.70 \%$ \\
\hline 11 & 1100 & 1116 & 16 & $1.45 \%$ \\
\hline 12 & 1200 & 1218 & 18 & $1.50 \%$ \\
\hline 13 & 1300 & 1317 & 17 & $1.31 \%$ \\
\hline 14 & 1400 & 1416 & 16 & $1.14 \%$ \\
\hline 15 & 1500 & 1518 & 18 & $1.20 \%$ \\
\hline \multicolumn{4}{|c|}{ Rata-rata } \\
\hline
\end{tabular}

Hasil dari pengujian sensor flowmeter dengan pengujian menggunakan gelas ukur tingkat persentase error pada pembacaan sensor flowmeter pada nomor 1 dengan error $6.00 \%$, nomor 2 dengan eror $7.50 \%$. dan seterusnya dengan 15 kali percobaan yang dimana rata -rata error $3.16 \%$. Dengan begitu bisa dikatakan bahwa keakurasian pada sensor flowmeter cukup akurat dengan berbandingan nilai volume air dengan satuan ml pada gelas ukur dan pembacaan Arduino.

\subsection{Pengujian Sensor Turbidity}

Dilakukan pengujian kekeruhan terhadap beberapa sampel air kolam ikan lele dapat dilihat pada Tabel 5.

Tabel 5. Pengujian Sensor Turbidity

\begin{tabular}{|c|c|}
\hline Foto Air kolam & $\begin{array}{c}\text { Nilai Keruh } \\
\text { (Sensor Turbididy) }\end{array}$ \\
\hline & $1.80 \mathrm{NTU}$ \\
\hline & $3.48 \mathrm{NTU}$ \\
\hline & \\
\hline & $5.93 \mathrm{NTU}$ \\
\hline & \\
\hline
\end{tabular}


Hasil dari pengujian sensor turbidity dengan memakai air kolam seperti Tabel 5 pada tabel dengan mengetahui tingka $\mathrm{t}$ keruh air kolam dengan nilai yang diperoleh pada sensor turbidity. Pada pengujian tingkat keruh dengan menggunakan sensor turbidity yakni nilai yang diperoleh berpengaruh pada sistem pantau air kolam jika tingkat keruh kolam melebihi batas normal akan berpengaruh pada ikan dan bisa membuat ikan mati.

\subsection{Pengujian Motor Servo}

Dilakukan pengujian motor servo terhadap penggaris busur 180 derajat. Berikut hasil dari pengujian motor servo dengan penggaris busur dapat dilihat pada Tabel 6.

Tabel 6. Pengujian Motor Servo

\begin{tabular}{|c|c|c|c|c|}
\hline No & Sudut Servo & Sudut Busur & Selisih & Error \\
\hline 1 & $0^{\circ}$ & $0^{\circ}$ & 0 & $0 \%$ \\
\hline 2 & $30^{\circ}$ & $28^{\circ}$ & 2 & $6.67 \%$ \\
\hline 3 & $60^{\circ}$ & $59^{\circ}$ & 1 & $1.67 \%$ \\
\hline 4 & $90^{\circ}$ & $88^{\circ}$ & 2 & $2.22 \%$ \\
\hline 5 & $120^{\circ}$ & $118^{\circ}$ & 2 & $1.67 \%$ \\
\hline 6 & $150^{\circ}$ & $147^{\circ}$ & 3 & $2.00 \%$ \\
\hline 7 & $180^{\circ}$ & $178^{\circ}$ & 2 & $1.11 \%$ \\
\hline \multicolumn{5}{|c|}{ Rata-rata } \\
\hline
\end{tabular}

Hasil pengujian motor servo dilakukan dengan membandingkan alat ukur penggaris busur $180^{\circ}$ untuk mengetahui nilai satuan derajat pada motor servo yang dimana persentase rata -rata eror nya $2.20 \%$. Nilai derajat yang diperoleh cukup akurat dengan membandingkan alat ukur penggaris busur, persentase error tersebut didapatkan oleh dari nilai selisih di bagi dengan nilai alat ukur penggaris kemudian dikali dengan $100 \%$ maka diperoleh nilai persentasi error tersebut.

\subsection{Pengujian Sistem Pakan}

Pengujian pada sistem pakan ini dilakukan dengan pengujian pada kinerja komponen motor servo dengan melihat ukuran pakan 1 sesi dapat dilihat pada Gambar 5.

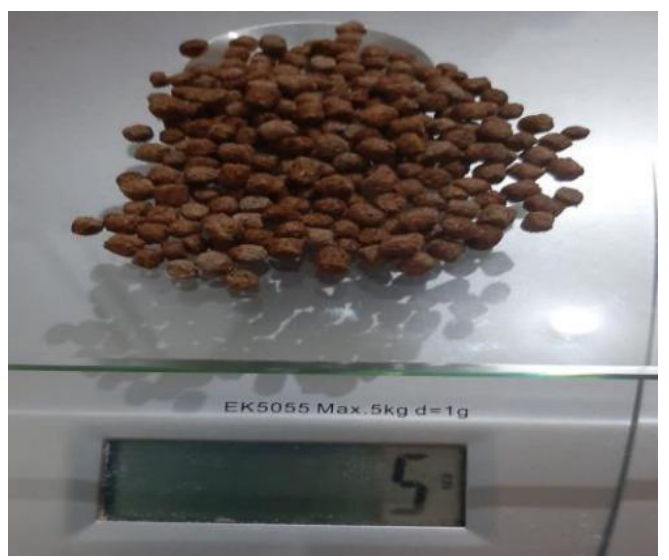

Gambar 5. Pengujian Sistem Pakan
Hasil pengujian sistem pakan tersebut telah di ukur dari berat pa kan ikan yang dikeluarkan dalam 1 sesi sebanyak $5 \mathrm{gr}$ sebanding dengan \pm 2 sendok makan. Sistem pakan ini bekerja sesuai jam yang telah diatur, dengan pemberian pakan dua kali setiap hari pada pada pukul 10.00 pagi dan pukul 17.00 sore.

\subsection{Pengujian Sistem Pestisida}

Pengujian pada sistem pestisida ini dilakukan dengan pengujian pada kinerja komponen motor servo sama seperti sistem pakan dengan melihat ukuran pestisida 1 sesi dapat dilihat pada Gambar 6.

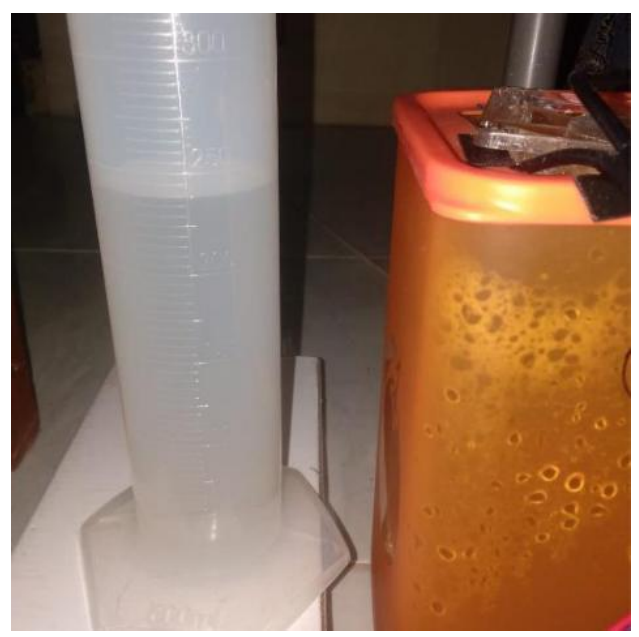

Gambar 6. Pengujain Sistem Pestisida

Hasil dari pengujian sistem pestisida tersebut awal mula cairan pestisida senilai $300 \mathrm{ml}$ gelas ukur. Kemudian dilakukan pengujian selama 5 jam dengan keadaan mist maker/ pembuat kabut dan DC Fan/ kipas menyala . Cairan pestisida tersebut diukur kembali menjadi senilai 240ml gelas ukur. Sistem pestisida ini bekerja sesuai jam yang telah diatur, dengan pemberian pestisida sehari 1 kali pada waktu pagi jam 11.00. Sistem pestisida tersebut mengeluarkan kabut selama 5 detik dalam 1 sesi berkurangnya ukuran pestisida sebesar $8 \mathrm{ml}$. Jadi dari pengujian sistem pestisida ini bahwa berkurangnya cairan pestisida selama 5 jam sebesar $60 \mathrm{ml}$ gelas ukur.

\subsection{Pengujian Sistem Padi Aquaponic}

Semua pengujian sistem padi Aquaponic dilakukan dengan menguji semua kinerja yaitu sistem, komponen dan eksekusi program . Instalasi dari padi Aquaponic dapat dilihat pada Gambar 7 . 


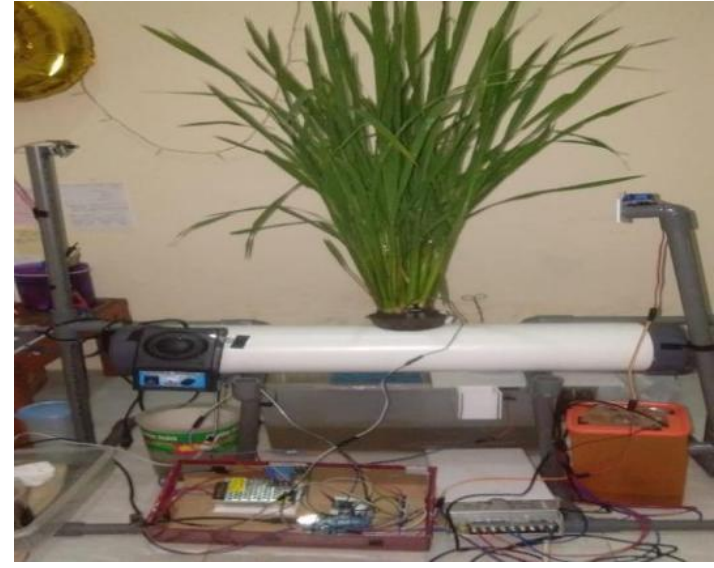

Gambar 7. Sistem Minimum Padi Aquaponic

Pengujian pada fungsionalitas Web Browser pada Sistem padi Aquaponic bisa dilihat pada Tabel 7.

Tabel 7. Fungsionalitas Pada Web Browser

\begin{tabular}{|c|l|c|c|c|}
\hline \multirow{2}{*}{ No } & \multirow{2}{*}{ Aspek Pengujian } & \multicolumn{3}{|c|}{ Web Browser } \\
\cline { 3 - 5 } & & Opera & Chrome & Microsoft Edge \\
\hline 1 & Fungsi Login & $\checkmark$ & $\checkmark$ & $\checkmark$ \\
\hline 2 & Tampilan Kamera & $\checkmark$ & $\checkmark$ & $\checkmark$ \\
\hline 3 & Halaman Monitoring & $\checkmark$ & $\checkmark$ & $\checkmark$ \\
\hline 4 & Notifikasi & $\checkmark$ & $\checkmark$ & $\checkmark$ \\
\hline 5 & Halaman Grafik & $\checkmark$ & $\checkmark$ & $\checkmark$ \\
\hline 6 & Halaman Abnormal & $\checkmark$ & $\checkmark$ & $\checkmark$ \\
\hline 7 & Responsive & $\checkmark$ & $\checkmark$ & $\checkmark$ \\
\hline
\end{tabular}

Hasil pengujian fungsional pada sistem aplikasi yang telah dibuat sudah berjalan dengan baik pada web browser Opera, Google Chrome dan Microsoft Edge yaitu tampilan login dan semua fungsi pada halaman utama seperti panel data atau tabel, panel data grafik, panel data abnormal dan tampilan logout berfungsi dengan baik serta semua responssif dari aplikasi dan alat bisa berjalan dengan baik. Karena aplikasi merupakan Website rensponsif yang dibuat menggunakan pemrogramman PHP.

\subsection{Tampilan Home}

Tampilan Home digunakan untuk monitoring data terakhir dan terbaru dari sensor dan waktu pada Sistem Padi Aquaponic, serta tampilan streaming dari kamera ESP32-Cam pada Gambar 8.

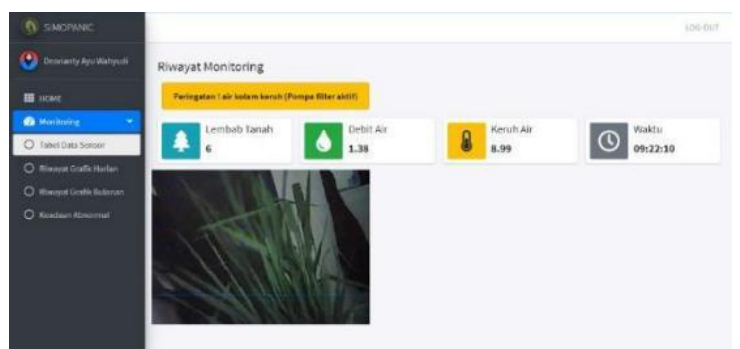

Gambar 8. Tampilan Home

\subsection{Tampilan Menu Data Monitoring}

Pada Tampilan Menu Data ditampilkan riwayat data sensor dan keterangan pada tingkat keruh air kolam pada Gambar 9.
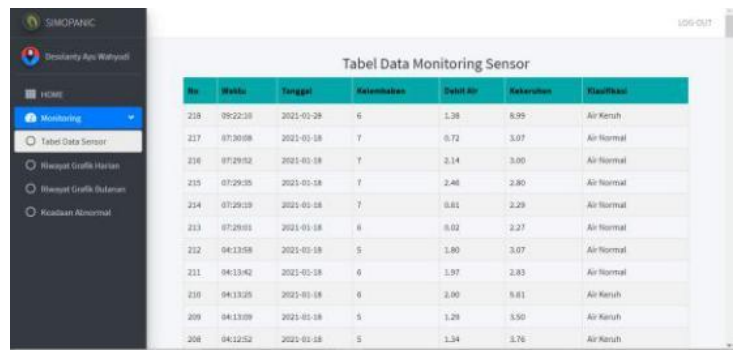

Gambar 9. Tampilan Menu Data Monitoring

\subsection{Tampilan Menu Grafik}

Pada Tampilan Menu Grafik disajikan 3 data grafik dari sensor kelembaban, debit air, dan keruh air kolam pada Gambar 10.
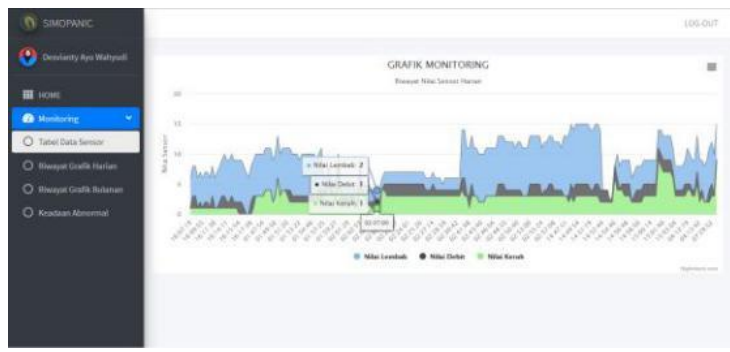

Gambar 10. Tampilan Menu Grafik

\subsection{Tampilan Menu Keadaan Abnormal}

Pada Tampilan Menu Keadaan Abnormal ditampilkan riwayat keadaan pada pompa kolam dan filtering air pada Gambar 11.

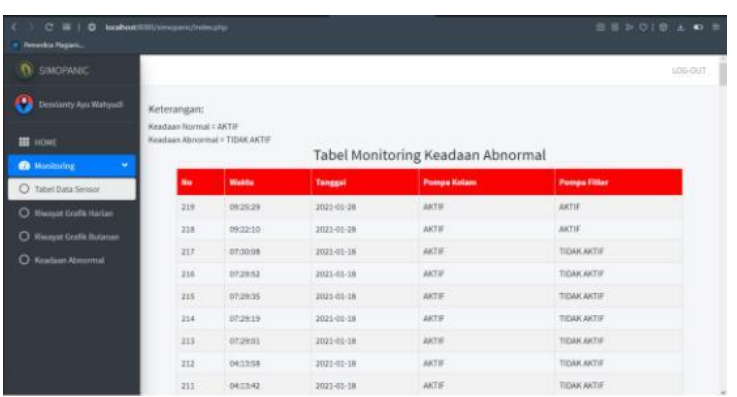

Gambar 11. Tampilan Menu Keadaan Abnormal 


\subsection{Tampilan Notifikasi}

Pada Tampilan Notifikasi ditampilkan pada halaman Home sebagai peringatan kuras air kolam ikan pada Gambar 12.

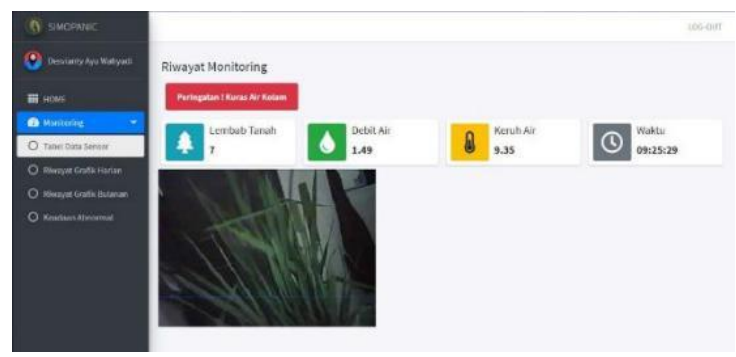

Gambar 12. Tampilan Notifikasi

\section{KESIMPULAN DAN SARAN}

\subsection{Kesimpulan}

Dari beberapa tahap uji dan perbandingan yang sudah dilakukan, diperoleh kesimpulan antara lain :

1. Perancangan sistem padi Aquaponic dengan menerapkan konsep IoT yang dapat dimonitoring kondisinya secara visual lewat aplikasi telah berhasil memonitoring adanya hama seperti burung karena dengan menggunakan kamera ESP32-Cam, monitoring nilai dari sensor soil moisture, flowmeter dan turbidity. kemudian sistem otomatis pada pemberian pakan dan pestisida secara otomatis berhasil sesuai pengaturan waktu yang telah di tentukan. Dan filtering air kolam sudah berfungsi otomatis dengan baik ketika deteksi air kolam keruh.

2. Sistem monitoring kadar lembab tanah, debit air, tingkat keruh, kamera pantau, pemberian pestisida, dan pakan ikan efektif dapat dimonitoring pada website dengan menggunakan modul ESP8266.

3. Sistem yang dibuat merupakan sistem pemantauan hama burung, tingkat kelembaban ta nah, debit air, serta kekeruhan air kolam.

4. Dari hasil uji sensor diketahui mempunyai ratarata prsentase error untuk sensor soil moisture $3.49 \%$ dan sensor flowmeter $3.16 \%$.

5. Pembacaan sensor turbidity mampu mendeteksi tingkat kekeruhan air kolam serta mampu mengontrol otomatis pada filter air kolam .

6. Dari hasil pengujian ESP8266 diketahui bahwa waktu pengiriman dan waktu tampil pada web delay selama 5 detik.

7. Dari hasil pengujian kamera ESP32-Cam diketahui bahwa nilai IP yang diberikan tetap.

8. Website berjalan dengan sempurna pada web browser yang sudah di uji yaitu Opera, Google Chrome dan Microsoft Edge karena aplikasi merupakan Website responsif yang dibuat menggunakan PHP.

\subsection{Saran}

Adapun saran untuk penelitian selanjutnya antara lain :
1. Untuk pengembangan ke depan, agar memperbanyak lagi sensor untuk parameter sistem padi Aquaponic seperti sensor suhu tanah dan sensor ph air tanah.

2. Menggunakan sensor yang sensifitasnya lebih baik, agar pembacaan nilai sensor lebih akurat

3. Agar lebih sempurna untuk pengendalian hama dibuat secara otomatis pada sistem speakernya

\section{DAFTAR PUSTAKA}

[1] Y. T. Dhahiyat, Y. Rizal, Ahmad dan Zahidah, "International Journal of Agriculture and Environmental Research," Aquaponics: a sustainable fishery productions system that provides research projects for undergraduate fisheries students, p. 4, 2018.

[2] J. Rakocy, D. Masser dan T. Losordo, "USA: Southern Regional Aquaqulture Center," Recirculating Aquaculture Tank Production System, 2006.

[3] jimmycurug, "Pengenalan Akuaponik," 21 September 2019. [Online]. Available: http://jirifarm.com/2018/09/21/pengenalanakuaponik/.

[4] D. Ratnawati dan R. B. Setiadi, "Jurnal Dinamika Vokasional Teknik Mesin," Techno-Pest Control Berbasis IOT untuk Proteksi Tanaman Padi, pp. 121-134, 2019.

[5] E. Tuluk, B. Irawadi dan A. W. Soejono, "Jurnal Teknologi Informasi," Implementasi Alat Pengusir Hama Burung di Area Persawahan dengan Menggunakan Gelombang Ultrasonik Berbasis Mikrokontroler Atmegal68, pp. 121-134, 2012.

[6] A. Mujadin, "Jurnal Al-Azhar Indonesia Seri Sains dan Teknologi," Prototype Chamber Pengaturan Suhu, Kelembaban dan Growing LED Tanaman Aeroponic, pp. 44-48, 2015.

[7] R. Triady, D. Triyanto dan Ilhamsyah, "Jurnal Coding Sistem Komputer Untan," Prototipe Sistem Keran Air Otomatis Berbasis Sensor Flowmeter pada Gedung Bertingkat, pp. 2534, 2015.

[8] A. F. Taufiqurrohman, S. A. Wibowo dan F. Ariwibisono, "Jurnal Mahasiswa Teknik Informatika," Penerapan IoT Untuk Monitoring Onlione Penggunaan Kadar Infus dan Kondisi Pasien Yang Sedang Membutuhkan Perawatan, pp. 7-13, 2020.

[9] Chandra dan R. Nathaniel, "Fakultas Ilmu Hayati Universitas Surya ," Internet OfThings dan Embedded System UntukIndonesia, pp. 243-912, 2014.

[10] W. Budiharto, "School of Computer Science, Bina Nusantara University," Inovasi Digital di Industri Smart Farming: Konsep dan Implementasi Digital Innovation in the Smart Farming Industry; Concept and Implementation, pp. 31-37, 2019

[11] dewaweb, "Pengenalan Website,"2019". [Online]. Available: https://www.dewaweb.com 